\title{
Prediction and repeatability of milk coagulation properties and curd-firming modeling parameters of ovine milk using Fourier-transform infrared spectroscopy and Bayesian models
}

\author{
A. Ferragina, ${ }^{*}$ C. Cipolat-Gotet, ${ }^{*}$ A. Cecchinato, ${ }^{*}$ M. Pazzola, $\dagger$ M. L. Dettori, ${ }^{*}$ G. M. Vacca, $\dagger^{1}$ and G. Bittante ${ }^{*}$ \\ *Department of Agronomy, Food, Natural Resources, Animals and Environment (DAFNAE) University of Padova, \\ viale dell'Università 16 - 35020 Legnaro (PD), Italy \\ †Department of Veterinary Medicine, University of Sassari, Via Vienna 2, 07100 Sassari, Italy
}

\begin{abstract}
The aim of this study was to apply Bayesian models to the Fourier-transform infrared spectroscopy spectra of individual sheep milk samples to derive calibration equations to predict traditional and modeled milk coagulation properties (MCP), and to assess the repeatability of MCP measures and their predictions. Data consisted of 1,002 individual milk samples collected from Sarda ewes reared in 22 farms in the region of Sardinia (Italy) for which MCP and modeled curdfirming parameters were available. Two milk samples were taken from 87 ewes and analyzed with the aim of estimating repeatability, whereas a single sample was taken from the other 915 ewes. Therefore, a total of 1,089 analyses were performed. For each sample, 2 spectra in the infrared region 5,011 to $925 \mathrm{~cm}^{-1}$ were available and averaged before data analysis. BayesB models were used to calibrate equations for each of the traits. Prediction accuracy was estimated for each trait and model using 20 replicates of a training-testing validation procedure. The repeatability of MCP measures and their predictions were also compared. The correlations between measured and predicted traits, in the external validation, were always higher than 0.5 (0.88 for rennet coagulation time). We confirmed that the most important element for finding the prediction accuracy is the repeatability of the gold standard analyses used for building calibration equations. Repeatability measures of the predicted traits were generally high $(\geq 95 \%)$, even for those traits with moderate analytical repeatability. Our results show that Bayesian models applied to Fourier-transform infrared spectra are powerful tools for cheap and rapid prediction of important traits in ovine milk and, compared with other methods, could help in the interpretation of results.
\end{abstract}

\footnotetext{
Received October 28, 2016.

Accepted January 28, 2017.

${ }^{1}$ Corresponding author: gmvacca@uniss.it
}

Key words: Fourier-transform infrared spectroscopy, Bayesian, ovine milk, milk coagulation properties, curd-firming modeling

\section{INTRODUCTION}

Sheep milk is mainly used for cheese production (Zhang et al., 2006; FAOSTAT, 2015). Many traditional high-quality cheeses in the European Union are made using ovine milk and are often labeled with protected designation of origin (PDO) certification (Lerma-García et al., 2010).

It is important for both the dairy industry and the milk payment system to obtain quality parameters for the cheesemaking aptitude of milk (Pellegrini et al., 1997; Sevi et al., 2000; Jaramillo et al., 2008; Abilleira et al., 2010). Several techniques and instruments are used to analyze milk coagulation properties (MCP) in ovine as well as bovine species (Bencini, 2002). Traditional MCP, determined by mechanical lactodynamographic instruments, are single point measurements of rennet coagulation time (RCT, min), curd-firming time $\left(\mathbf{k}_{\mathbf{2 0}}, \mathbf{m i n}\right)$, and curd firmness [over $30 \mathrm{~min}\left(\mathbf{a}_{\mathbf{3 0}}\right)$, $\mathrm{mm}$. However, in the bovine species, analysis of milk coagulation by traditional MCP is inadequate because of the growing number of noncoagulating (no MCP trait available) and late-coagulating (no $\mathrm{k}_{20}$ available) samples. The duration of the lactodynamographic test of $30 \mathrm{~min}$ is too short, and the 3 traditional single-point traits are inadequate for capturing important information generated during the test (Bittante et al., 2012, 2013). Traditional MCP cannot fully represent milk coagulation and curd-firming process in the ovine species, but for the opposite reason: sheep milk coagulates much faster than bovine milk, curd firming is more rapid and intense, and curd syneresis begins earlier (Bittante et al., 2012). Vacca et al. (2015), in a large survey on dairy Sarda sheep, reported that about two-thirds of milk samples reached the maximum curd firmness within 30 min after rennet addition. This means that only one- 
third of $\mathrm{a}_{30}$ is measured in the growing phase of the lactodynamographic curve (as it normally happens for bovine milk samples), and two-thirds in the decreasing phase after the attainment of maximum curd firmness when syneresis is prevailing on curd firming (Bittante et al., 2014). To better explore the coagulation and curd-firming phases of milk, Bittante (2011) proposed a new approach based on modeling curd-firming over time $\left(\mathbf{C F}_{\mathbf{t}}\right)$, and, to also predict syneresis, on prolonging the duration of the test (Bittante et al., 2013). The new modeled parameters [modeled rennet coagulation time $\left(\mathbf{R C T}_{\mathbf{e q}}, \mathrm{min}\right)$; asymptotic potential value of curd firmness at an infinite time $\left(\mathbf{C F}_{\mathbf{P}}, \mathbf{m m}\right)$; curd-firming instant rate constant $\left(\mathbf{k}_{\mathrm{CF}}, \% \times \min ^{-1}\right)$; syneresis instant rate constant $\left(\mathbf{k}_{\mathbf{S R}}, \% \times \min ^{-1}\right)$; maximum curd firmness $\left(\mathbf{C F}_{\max }, \mathbf{m m}\right)$; time to reach $\mathrm{CF}_{\max }\left(\mathbf{t}_{\max }\right.$, min)] overcome the disadvantages of traditional MCP and also provide information about the syneresis process. The use of $\mathrm{CF}_{\mathrm{t}}$ modeling has already been tested on sheep milk from Alpine breeds (Bittante et al., 2014) and Sarda (Vacca et al., 2015).

Mechanical analysis is required to determine traditional MCP and, consequently, modeled MCP. These techniques are expensive and time-consuming, making it impossible to perform the analyses routinely on a large number of animals.

The income from a single ewe is lower than that from a dairy cow, and the cost of phenotyping with respect to its return is proportionally higher (Carta et al., 2008). Therefore, it is important to study new analytical techniques that can reduce the cost of phenotyping.

Fourier-transform infrared spectroscopy (FTIR) in the range of near- and mid-infrared wavelengths is a technique widely used for routine analysis in many laboratories and by breeders' associations in their milk quality-recording systems. Fourier-transform infrared spectroscopy is a cheap and fast analytical method, already recognized for predicting major milk components (ICAR, 2012). Many studies have assessed FTIR prediction of new phenotypes in cow milk (De Marchi et al., 2014), including traditional MCP (Dal Zotto et al., 2008). The feasibility of using FTIR prediction for genetic improvement has also been demonstrated (Cecchinato et al., 2009).

The species of ruminant influences the composition and properties of milk, and, as a consequence, the FTIR spectra. In particular, specific calibrations are needed for sheep, which are different from those for cows and goats (Nicolaou et al., 2010).

The accuracy of predictions obtained by FTIR depends on many factors, among them the reliability of the reference values and chemometric techniques (i.e., selection of wavelengths, pretreatment of spectra, and the statistical model). The selection of informative variables has been shown to be important for removing noise in the spectra and for improving the equation, and for predicting milk fatty acids in ewes, cows, and goats using the partial least squares regression model (Ferrand-Calmels et al., 2014; Caredda et al., 2016). Ferragina et al. (2015) reported that Bayesian models commonly used for genomic data, in particular the variable selection model BayesB, could improve the prediction of some cow milk parameters, including RCT. Moreover, that technique offers some insight into the importance of individual wavelengths for trait prediction. Thus, the aim of our study was to apply the BayesB model to the FTIR spectra of a large number of individual sheep milk samples to predict traditional and modeled MCP, and compare the repeatability of the measured and predicted traits.

\section{MATERIALS AND METHODS}

\section{Animals, Milk Sampling, and Coagulation Properties}

Details concerning the animals and the sampling procedure have already been described in Pazzola et al. (2014). For the present study, we sampled 1,002 Sarda ewes reared in 22 farms in the region of Sardinia, Italy. Two milk samples were taken from 87 randomly selected ewes reared on 18 farms and analyzed with the aim of estimating repeatability, whereas 1 sample was taken from the other 915 ewes (about 1 double-sampled for every 10 single-sampled ewes) and analyzed (1,089 samples and analyses in total). The single-sample set and the double-sample set were statistically analyzed separately.

Analyses for chemical composition (protein, casein, fat, lactose, and urea) were carried out using a MilkoScan FT6000 (Foss Electric A/S, Hillerød, Denmark). Calibration was done according to the following reference methods: fat (ISO 1211:IDF 1; gravimetric method, Rose-Gottlieb; ISO, 2010); protein (ISO 8968e2:IDF 20; titrimetric method, Kjeldahl; ISO, 2014); casein (ISO 17997e1:IDF 29; titrimetric method, Kjeldahl; ISO, 2004); and lactose (ISO 5765:IDF 79; enzymatic method; ISO, 2002).

Milk samples were mixed into a $200-\mu \mathrm{L}$ rennet solution [Hansen Naturen Plus 215 (Pacovis Amrein AG, Bern, Switzerland), with $80 \pm 5 \%$ chymosin and 20 $\pm 5 \%$ pepsin and 215 international milk clotting units (IMCU) $/ \mathrm{mL}$, diluted to $1.2 \%$ (wt./vol) in distilled water to obtain a solution with $0.0513 \mathrm{IMCU} / \mathrm{milk} \mathrm{mL}$ ] to achieve the traditional single-point MCP extended to 60 min [RCT, $\mathrm{k}_{20}, \mathrm{a}_{30}$, and curd firmness over 45 and $60 \mathrm{~min}\left(\mathbf{a}_{45}\right.$ and $\mathbf{a}_{60}$, respectively)] were measured using a Formagraph (Foss Italia S.P.A., Padua, Italy), as described in Pazzola et al. (2014). The $240 \mathrm{CF}_{\mathrm{t}}$ mea- 
sures per sample ( 1 every $15 \mathrm{~s}$ for $60 \mathrm{~min}$ after rennet addition) were used to estimate the parameters of the individual equations $\left(\mathrm{RCT}_{\mathrm{eq}}, \mathrm{CF}_{\mathrm{P}}, \mathrm{k}_{\mathrm{CF}}\right.$, and $\left.\mathrm{k}_{\mathrm{SR}}\right)$, and the derived traits relative to the maximum curd firmness of each sample $\left(\mathrm{CF}_{\max }\right.$ and $\left.t_{\max }\right)$. As reported in Vacca et al. (2015), 2 model equations were used: the 4 -parameter (4p) model described by Bittante et al. (2013)

$$
\left\{\mathrm{CF}_{\mathrm{t}}=\mathrm{CF}_{\mathrm{P}}\left[1-e^{-\mathrm{k}_{\mathrm{CF}} \times\left(t-\mathrm{RCT}_{\mathrm{eq}}\right)} \times e^{-\mathrm{k}_{\mathrm{SR}} \times\left(t-\mathrm{RCT}_{\mathrm{eq}}\right)}\right]\right\},
$$

and the 3-parameter (3p) model described in Bittante (2011)

$$
\left\{\mathrm{CF}_{\mathrm{t}}=\mathrm{CF}_{\mathrm{P}}\left[1-e^{-\mathrm{k}_{\mathrm{CF}} \times\left(t-\mathrm{RCT}_{\mathrm{eq}}\right)}\right]\right\}
$$

where $e=$ exponent and $t=$ time from rennet addition.

\section{FTIR Spectra and Statistical Analysis}

Spectra Editing. Prior to data analysis, the spectra (each single wavenumber) were standardized to a null mean and a unit sample variance. Mahalanobis distances were calculated by means of the "mahalanobis" function of the R software (R Core Team, 2015), the inverse of the spectral covariance matrix and the "center" statement as a vector of 0 . The spectra with a distance value greater than the mean plus 3 standard deviations were classified as outliers. The spectra were used without mathematical pretreatment, except the aforementioned standardization. Using the BayesB method, we also used the spectral regions typical of water absorption, which are characterized by high variability and, in many cases, are not used for the calibration (Bittante and Cecchinato, 2013).

Statistical Analysis. Separate models were fitted for all the traits. In the present study, we used a Bayesian model, specifically the BayesB model, implemented in the BGLR package of the R software (de los Campos and Perez Rodriguez, 2015), as previously described by Ferragina et al. (2015). Basically phenotypes were regressed on standardized spectra covariates using the linear model

$$
y_{i}=\beta_{0}+\sum_{j=1}^{1,060} x_{i j} \beta_{j}+\varepsilon_{i},
$$

where $y_{i}$ is the measured phenotype of $i$ th sample, $\beta_{0}$ is an intercept, $\left\{x_{i j}\right\}$ are standardized FTIR spectra-derived wavelength data $(j=1, \ldots, 1,060), \beta_{j}$ are the effects of each of the wavelengths, and $\varepsilon_{i}$ are model residuals assumed to be independent and identically distributed with normal distribution centered at zero with variance $\sigma_{\varepsilon}^{2}$. Given the above assumption, the conditional distribution of the data given effects and variance parameters was

$$
P(y \mid \theta)=\prod_{i=1}^{n} N\left(\mu_{i}, \sigma_{\varepsilon}^{2}\right),
$$

where $\theta$ represents the collection of model parameters $\theta=\left\{\beta_{0}, \beta, \sigma_{\varepsilon}^{2}\right\}, N=\left(\mu_{i}, \sigma_{\varepsilon}^{2}\right)$ is a normal distribution centered at $\mu_{i}=\beta_{0}+\sum_{j=1}^{1,060} x_{i j} \beta_{j}$, and with variance $\sigma_{\varepsilon}^{2}$, and $\beta\left\{\beta_{i j}\right\}$ is a vector containing the effects of the individual spectra-derived wavelengths. Specification of the Bayesian model is completed by assigning prior distribution to the unknowns, $\theta$. In the Bayesian models considered here, the prior density was as follows:

$p(\theta)=N\left(\beta_{0} \mid 0,1 \times 10^{5}\right) \chi^{-2}\left(\sigma_{\varepsilon}^{2} \mid d f_{\varepsilon}, S_{\varepsilon}\right)\left\{\prod_{j=1}^{1,060} p\left(\beta_{j} \mid \Omega\right)\right\} p(\Omega)$.

Here, the intercept is assigned a normal prior with a very large variance, the residual variance is assigned a scaled-inverse chi-squared density with degree of freedom $d f_{\varepsilon}$ and scale parameters $S_{\varepsilon}$, and the effects of wavelengths are assigned independent and identically distributed priors, $p\left(\beta_{j} \mid \Omega\right)$, indexed by a set of hyperparameters, $\Omega$, which are also treated as random. The default values of the built-in BGLR rules were used for all the hyperparameters of the model, and the inferences were based on 30,000 iterations and a burn-in of 10,000 .

Assessment of Prediction Accuracy Through Cross-Validation. The accuracy of the model and the prediction equation were assessed by a trainingtesting procedure using the sample set with 915 single measures. A training data set ( $80 \%$ of the total records) was used to build the equation, and a testing data set (20\% of the total) was used as validation. The samples in the training and testing sets were randomly assigned and the training-testing procedure was repeated 20 times for each trait, changing the training and testing set samples each time. The training-testing procedure was used for all the 14 studied traits. For each of the 20 training-testing trials of the prediction procedure of one trait, the observed and the predicted values of the testing data set were used to calculate the coefficient of correlation of validation $\left(\mathbf{R}_{\mathrm{VAL}}\right)$ and the root mean square error of validation $\left(\mathbf{R M S E}_{\mathrm{VAL}}\right)$. Also the coefficient of correlation of calibration $\left(\mathbf{R}_{\mathrm{CAL}}\right)$ was calculated using the measured and predicted values of each training data set. The final $\mathrm{R}_{\mathrm{CAL}}, \mathrm{R}_{\mathrm{VAL}}$ and $\mathrm{RMSE} \mathrm{VAL}_{\mathrm{VAL}}$ 
for each trait are the averages of the 20 training-testing trials carried out.

Final Prediction Equation, External Validation, and Repeatability. For each trait, a further calibration was carried out using the entire set of single measure samples (915 samples) as training data set, and the obtained prediction equations were externally validated using the data set of double measure samples. The coefficient of correlation between predicted and measured values of external validation $\left(\mathbf{R}_{\mathrm{EXT}}\right)$ and the root mean square error of validation $\left(\mathbf{R M S E}_{\mathbf{E X T}}\right)$ were calculated. Also the estimated coefficients for each model and the Pearson correlations between the milk absorbance at a given wavelength and each phenotype were studied. To better describe the results along the spectral range, we divided the spectrum in 5 regions (Bittante and Cecchinato; 2013): short wave infrared (SWIR, often called near-infrared or NIR), transition between near- and mid-infrared (SWIR-MWIR), MWIR-1, MWIR-2, and transition between mid- and long-infrared (MWIR-LWIR).

The repeatability coefficients of the measured and predicted values were also estimated and compared. Estimation of variance components was accomplished, separately for each MCP and CF phenotype, using the SAS 9.4 MIXED procedure (SAS Institute Inc., Cary, $\mathrm{NC}$ ), and the following linear model:

$$
y_{i j k}=\mu+\text { Herd } / \text { Date }_{i}+\text { Animal }_{j}+e_{i j k} \text {, }
$$

where $y_{i j k}$ is the observed trait (measured and predicted $\mathrm{MCP}$ and $\mathrm{CF}$ phenotypes); $\mu$ is the overall intercept of the model; Herd/Date ${ }_{i}$ is the random effect of the $i$ th class of herd-test date; Animal $_{j}$ is the random effect of the jth animal; and $e_{i j k}$ is the random residual. Herd/ Date, Animal, as well as residual, were assumed to be independently and normally distributed with a mean of zero and variance $\sigma_{\mathrm{HD}}^{2}, \sigma_{\text {animal }}^{2}$, and $\sigma_{e}^{2}$, respectively. Restricted maximum likelihood was used as the method of estimation of variance components.

The coefficient of repeatability (REP) was estimated as

$$
R E P=\frac{\sigma_{\mathrm{HD}}^{2}+\sigma_{\text {animal }}^{2}}{\sigma_{\mathrm{HD}}^{2}+\sigma_{\text {animal }}^{2}+\sigma_{e}^{2}} \times 100 .
$$

\section{RESULTS AND DISCUSSION}

\section{Traditional MCP and Curd-Firming Model Parameters}

Table 1 shows the descriptive statistics for the MCP measured by the Formagraph and for the $\mathrm{CF}_{\mathrm{t}}$ model parameters obtained using the $3 \mathrm{p}$ (without syneresis) and $4 \mathrm{p}$ (with syneresis) models on the set of single measure samples. The results of the traditional singlepoint MCP obtained in our study are very similar to those obtained from the same data set by Pazzola et al. (2014); in the case of $k_{20}$ and $\mathrm{a}_{30}$, they are also similar to the results obtained from the same breed, but different data sets, by Battacone et al. (2005) and Manca et al. (2016). The CFt parameters we found were similar to those from the Alpine sheep breeds (Bittante et al., 2014), with the sole exception of $\mathrm{k}_{\mathrm{CF}}$, which was smaller in the Sarda milk samples. Two models were used in this study: the $3 \mathrm{p}$ model described by Bittante (2011) and the 4p model described by Bittante et al. (2013). The $\mathrm{RCT}_{\text {eq }}$ obtained with the 2 models were almost identical and, on average, 1 min longer than the traditional RCT. The $3 \mathrm{p}$ model had a higher $\mathrm{k}_{\mathrm{CF}}$ and lower $\mathrm{CF}_{\mathrm{P}}\left(30.9 \% \times \mathrm{min}^{-1}\right.$ and $55.0 \mathrm{~mm}$, respectively) than the $4 \mathrm{p}$ model $\left(28.0 \% \times \min ^{-1}\right.$ and 61.1 $\mathrm{mm}$, respectively). Differences were due to the effect of syneresis taken into account in the latter but not the former model (Bittante et al., 2013). The time to achieve the maximum CF of $54.6 \mathrm{~mm}$ was $28.6 \mathrm{~min}$, not much different from that obtained with milk samples from Alpine breeds (Bittante et al., 2014).

\section{FTIR Prediction Models}

Analysis of MCP is an expensive, time-consuming technique, especially when individual milk samples at the population level need to be analyzed. Furthermore, as mentioned above, traditional MCP are not exhaustive in terms of describing the coagulation process of ewe milk (Bittante et al., 2014; Vacca et al., 2015); thus, they need to be integrated with supplementary information (i.e., $\mathrm{CF}_{\mathrm{t}}$ model parameters), which requires additional time and knowledge.

Interest has been growing in using FTIR technology to analyze milk and dairy products in recent decades because, with proper calibration, it is a fast and cheap technique (De Marchi et al., 2014). To our knowledge, no studies have used FTIR spectroscopy to predict traditional $\mathrm{MCP}$ - and $\mathrm{CF}_{\mathrm{t}}$-modeled parameters of ewe milk, so we were only able to compare the FTIR prediction results reported in the current paper with those obtained from cow milk and using different analyses of the references and calibration procedures.

Table 1 shows the prediction statistics for each trait. For $R_{\mathrm{CAL}}, \mathrm{R}_{\mathrm{VAL}}$, and $\mathrm{RMSE} \mathrm{E}_{\mathrm{VAL}}$, the average values and standard deviations of the 20 calibration rounds performed for each trait using the training-testing procedure are reported.

The averaged coefficients of correlation between the measured and predicted traits of the training data set $\left(\mathrm{R}_{\mathrm{CAL}}\right)$ varied from $89 \%(\mathrm{SD}=0.01)$ for the $3 \mathrm{RCT}$ 
Table 1. Descriptive statistics of traditional coagulation properties and curd-firming $\left(\mathrm{CF}_{\mathrm{t}}\right)$ model parameters (from 2 different models) and results of calibrations using Fourier-transform infrared spectra of individual milk samples

\begin{tabular}{|c|c|c|c|c|c|c|c|c|c|c|}
\hline Item $^{1}$ & \multicolumn{7}{|c|}{ Descriptive statistics $^{2}$} & \multicolumn{3}{|c|}{ Prediction statistics $^{3}$} \\
\hline $\mathrm{RCT}, \min$ & 894 & 8.9 & 4.1 & 5.1 & 16.3 & 2.7 & 14.3 & $0.89 \pm 0.01$ & $0.83 \pm 0.04$ & $2.3 \pm 0.35$ \\
\hline $\mathrm{k}_{20}, \min$ & 886 & 1.9 & 0.5 & 1.5 & 3.0 & 1.5 & 7.5 & $0.73 \pm 0.01$ & $0.67 \pm 0.03$ & $0.4 \pm 0.03$ \\
\hline $\mathrm{a}_{30}, \mathrm{~mm}$ & 889 & 50.2 & 11.6 & 29.4 & 64.4 & -0.8 & 3.2 & $0.69 \pm 0.01$ & $0.63 \pm 0.05$ & $9.0 \pm 0.56$ \\
\hline $\mathrm{a}_{45}, \mathrm{~mm}$ & 893 & 46.0 & 14.7 & 20.0 & 65.1 & -0.5 & 2.3 & $0.66 \pm 0.01$ & $0.58 \pm 0.05$ & $11.9 \pm 0.68$ \\
\hline $\mathrm{RCT}_{\mathrm{eq}}, \min$ & 894 & 9.9 & 4.0 & 6.0 & 17.4 & 2.6 & 13.9 & $0.89 \pm 0.01$ & $0.83 \pm 0.04$ & $2.3 \pm 0.34$ \\
\hline $\mathrm{CF}_{\mathrm{p}}, \mathrm{mm}$ & 850 & 55.0 & 7.3 & 42.4 & 64.9 & -0.7 & 3.7 & $0.71 \pm 0.01$ & $0.66 \pm 0.03$ & $5.5 \pm 0.35$ \\
\hline $\mathrm{k}_{\mathrm{CF}}, \% \times \min ^{-1}$ & 894 & 30.9 & 7.2 & 19.8 & 42.7 & 0.1 & 4.0 & $0.69 \pm 0.02$ & $0.58 \pm 0.06$ & $5.9 \pm 0.35$ \\
\hline \multicolumn{11}{|l|}{$\mathrm{CF}_{\mathrm{t}}$ modeling-4p } \\
\hline $\mathrm{RCT}_{\mathrm{eq}}, \min$ & 895 & 9.8 & 4.3 & 5.6 & 17.6 & 2.9 & 17.8 & $0.89 \pm 0.01$ & $0.82 \pm 0.05$ & $2.4 \pm 0.34$ \\
\hline $\mathrm{CF}_{\mathrm{p}}, \mathrm{mm}$ & 895 & 61.1 & 10.0 & 43.8 & 74.9 & -0.5 & 3.0 & $0.72 \pm 0.01$ & $0.69 \pm 0.03$ & $7.3 \pm 0.27$ \\
\hline $\mathrm{k}_{\mathrm{CF}}, \% \times \min ^{-1}$ & 895 & 28.0 & 11.9 & 13.5 & 47.8 & 1.8 & 10.0 & $0.58 \pm 0.02$ & $0.48 \pm 0.06$ & $10.4 \pm 0.97$ \\
\hline
\end{tabular}

${ }^{1}$ Traditional milk coagulation properties: RCT $=$ rennet coagulation time; $\mathrm{k}_{20}=$ curd firming time; $\mathrm{a}_{30}, \mathrm{a}_{45}$, and $\mathrm{a}_{60}=$ curd firmness 30,45 , and 60 min after rennet addition. $\mathrm{CF}_{\mathrm{t}}$ model parameters according to 3 - and 4-parameter models: $\mathrm{CF}_{\mathrm{p}}=$ asymptotical curd firmness; $\mathrm{k}_{\mathrm{CF}}=$ instant curd firming rate constant; $\mathrm{k}_{\mathrm{SR}}=$ instant syneresis rate constant; $\mathrm{CF}_{\max }=$ maximum curd firmness; $\mathrm{t}_{\max }=$ time from rennet addition to the attainment of the $\mathrm{CF}_{\max } . \mathrm{CF}_{\max }$ and $\mathrm{t}_{\max }$ traits were extracted from all curd firmness points $\left(\mathrm{CF}_{\mathrm{t}}\right)$ measured every $15 \mathrm{~s}$ by a lactodynamograph instrument for the 4-parameter model.

${ }^{2} \mathrm{P} 5=5$ th percentile; $\mathrm{P} 95=95$ th percentile.

${ }^{3} \mathrm{R}_{\mathrm{CAL}}, \mathrm{R}_{\mathrm{VAL}}$, and $\mathrm{RMSE}_{\mathrm{VAL}}=$ average $\pm \mathrm{SD}$ from 20 replications of the coefficient of correlation of calibration, of the coefficient of correlation of validation and of the root mean squared error of validation, respectively.

traits (the traditional and the 2 obtained by modeling all the $\mathrm{CF}_{\mathrm{t}}$ observations) to $55 \%(\mathrm{SD}=0.02)$ for the $\mathrm{k}_{\mathrm{SR}}$. For these same traits, the averaged correlation between measured and predicted traits in the testing data set $\left(\mathrm{R}_{\mathrm{VAL}}\right)$ ranged from $0.83(\mathrm{SD}=0.04)$ to 0.42 $(\mathrm{SD}=0.07)$, respectively. The $\mathrm{R}_{\mathrm{VAL}}$ and $\mathrm{R}_{\mathrm{CAL}}$ were strictly linked ( $\mathrm{r}=0.96)$; as expected, the former was always smaller than the latter, ranging from $3\left(\mathrm{CF}_{\mathrm{P}}\right.$ and $\left.\mathrm{CF}_{\max }\right)$ to $13\left(\mathrm{k}_{\mathrm{SR}}\right)$ percentage points.

Using the same prediction model and a large number of individual cow milk samples, Ferragina et al. (2015) find a prediction accuracy of $0.79\left(\mathrm{R}_{\mathrm{VAL}}\right)$ for $\mathrm{RCT}$, similar to our result (0.83). In their study on RCT and $\mathrm{a}_{30}$ prediction, Dal Zotto et al. (2008) used different instruments to measure the MCP and to acquire the FTIR spectra, as well as a different prediction model and mathematical treatment of the spectra. Their results (coefficient of correlation of cross-validation) for RCT and $\mathrm{a}_{30}$ prediction were 0.80 and 0.59 , respectively, whereas the results in the present study were 0.89 and 0.69 , respectively.

Validation of the calibration procedure based on FTIR spectra is more correctly carried out using real external samples, not those used for calibration or cross-validation. In the present study, the data set comprising 2 analyses of each of 87 ewes (174 data for each trait) never used for calibrations was used as the exter- nal data set. The $R_{\text {EXT }}$ was also similar to $R_{\text {CAL }}(r=$ 0.81 ), although the relationship between $R_{\mathrm{CAL}}$ and $\mathrm{R}_{\mathrm{VAL}}$ was emphasized $(r=0.96)$. Moreover, it is interesting to note (comparing Table 1 and Table 2) that $R_{\text {EXT }}$ is always greater than $R_{\mathrm{VAL}}$, the only exception being $\mathrm{k}_{20}$, and that the calibrations obtained using the BayesB method on the lactodynamographic traits of ovine milk seem to be effective in predicting those traits.

\section{Repeatability}

The reliability of the reference values significantly influence the accuracy of the prediction model (Caredda et al., 2016). The FTIR spectroscopy measures the transmission of more than 1,000 different waves. When the frequency of a wave is the same as the frequency of a chemical bond, absorption occurs, reflecting the amount of chemical bonds. Given that infrared spectroscopy is a secondary method for predicting the chemical composition of a sample, requiring prior calibration based on a set of spectra and relative references, spectra and reference values need to be of high quality to obtain a good calibration.

The MCP are characterized by a lower instrumental repeatability and reproducibility than analyses of milk chemical composition. We were able to calculate the coefficients of repeatability for all the measured and 
predicted traits studied in this work (Table 2) using a data set composed of 2 analyses for each of the animals.

The repeatability of the traits measured for sheep milk in the present study was similar to the repeatability measured in bovine species for both traditional single-point $\mathrm{MCP}$ and for modeled $\mathrm{CF}_{\mathrm{t}}$ equation parameters (Dal Zotto et al., 2008; Stocco et al., 2015, 2017).

The repeatabilities of the FTIR predicted traits were very high $(\geq 95 \%)$ for all traits because the $\sigma_{\text {aliquot }}^{2}$ was much lower for predicted than for measured traits (Table 2). This meant that the spectra (and chemical composition) of the 2 samples of each ewe were very similar and that the modest repeatability often found for the lactodynamographic traits is not due to sampling problems, but rather to instrumental problems.
Our results confirmed that prediction results were highly influenced by the repeatability of the references. Indeed, we found a strong correlation between $R_{\mathrm{CAL}}$ and the repeatability of the gold standard reference value (Figure 1). Improvement in the FTIR prediction accuracy depends on improvement in the repeatability of the gold standard analyses through technical modification or by using, for calibration, a data set composed of the averages of 2 or more replicates per sample.

\section{Use of FTIR-Selected Waves for Trait Interpretation}

A first step in evaluating the importance of milk absorbance at the individual 1,060 waves tested through FTIR is to examine the Pearson correlations between the milk absorbance at a given wavelength and a given

Table 2. Results from ANOVA, repeatability (REP), and statistics of prediction equations of traditional coagulation properties and curdfirming $\left(\mathrm{CF}_{\mathrm{t}}\right)$ model parameters (from 2 different models) using an external data set of individual milk ewes samples (87 animals doublesampled; 174 observations)

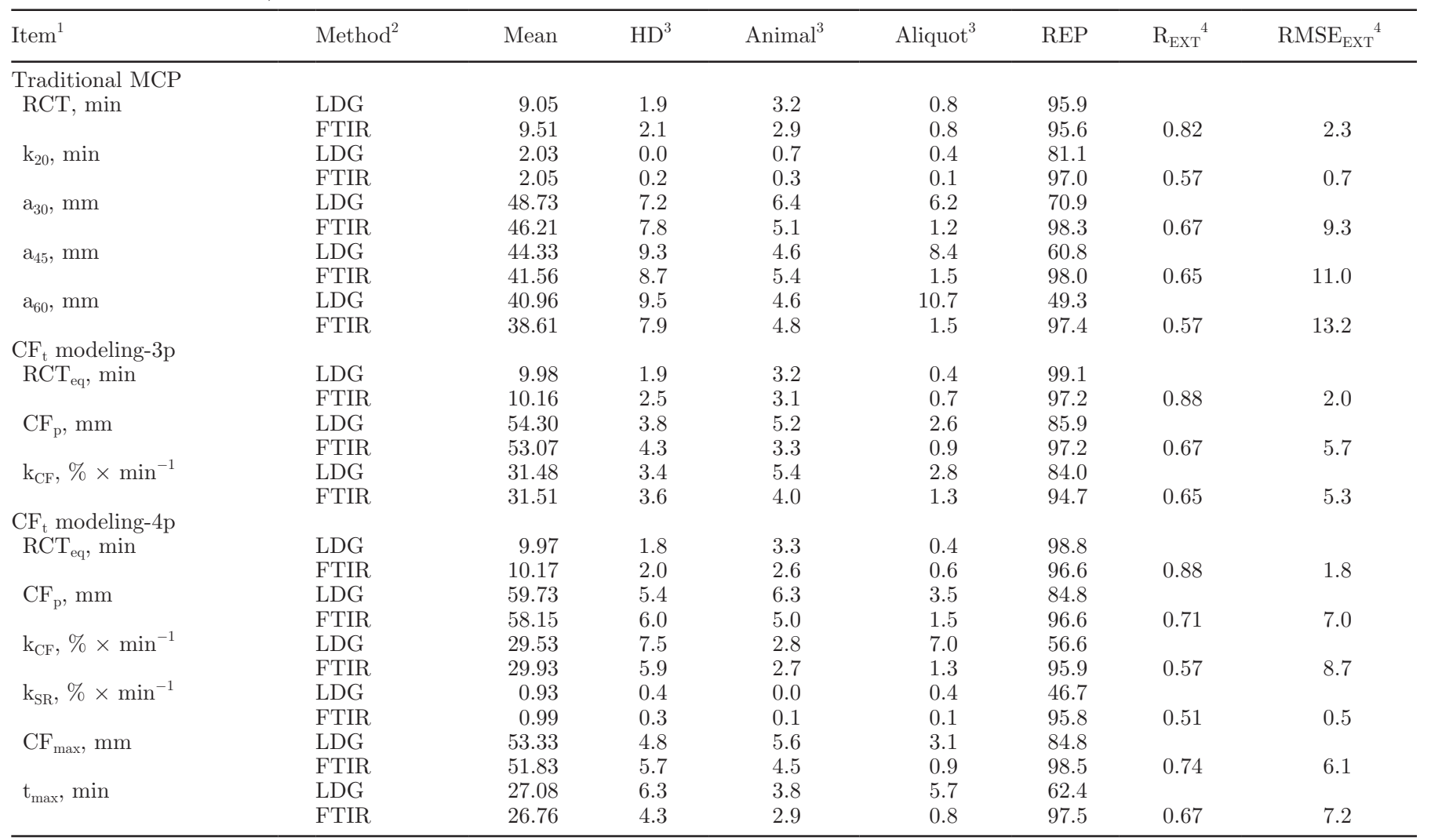

${ }^{1}$ Traditional milk coagulation properties $(\mathrm{MCP}): \mathrm{RCT}=$ rennet coagulation time; $\mathrm{k}_{20}=$ curd firming time; $\mathrm{a}_{30}, \mathrm{a}_{45}$, and $\mathrm{a}_{60}=$ curd firmness 30 , 45, and 60 min after rennet addition. $\mathrm{CF}_{\mathrm{t}}$ model parameters according to 3- and 4-parameter (3p and 4p) models: $\mathrm{CF}_{\mathrm{p}}=$ asymptotical curd firmness; $\mathrm{k}_{\mathrm{CF}}=$ instant curd firming rate constant; $\mathrm{k}_{\mathrm{SR}}=$ instant syneresis rate constant. $\mathrm{CF}_{\max }=$ maximum curd firmness; $\mathrm{t}_{\max }=$ time from rennet addition to the attainment of the $\mathrm{CF}_{\max } \cdot \mathrm{CF}_{\max }$ and $\mathrm{t}_{\max }$ traits were extracted from all curd firmness points $\left(\mathrm{CF}_{\mathrm{t}}\right)$ measured every $15 \mathrm{~s}$ by lactodynamograph instrument for $4 \mathrm{p}$.

${ }^{2} \mathrm{LDG}=$ lactodynamograph; FTIR = Fourier-transform infrared.

${ }^{3}$ Random factors [herd date (HD), animal, and aliquot] expressed as root of mean squared values.

${ }^{4} \mathrm{R}_{\mathrm{EXT}}, \mathrm{RMSE}_{\mathrm{EXT}}=$ coefficient of correlation and root mean squared error of validation for the external subset, respectively. 
lactodynamographic trait. As an example, Figure 2 illustrates the correlation with $\mathrm{RCT}$, which for the large majority of waves appears to be moderate, positive, or, more often, negative. The FTIR spectrum is fractionated in the 5 regions proposed by Bittante and Cecchinato (2013) for bovine milk. It can be seen that the absorbance of all the waves in the SWIR region (i.e., near-infrared or NIR, spans wavenumber 5,000 to 3,673 $\times \mathrm{cm}^{-1}$, corresponding to wavelengths from 2.00 to 2.72 $\mu \mathrm{m}$ and frequencies from 149.9 to $110.1 \mathrm{THz}$ ) had moderate negative correlations with RCT. In the second region of the spectrum, the SWIR-MWIR (spanning wavenumber 3,669 to $3,052 \times \mathrm{cm}^{-1}$, corresponding to wavelengths from 2.726 to $3,277 \mu \mathrm{m}$ and frequencies from 110.0 to $91.5 \mathrm{THz}$ ), the correlations with $\mathrm{RCT}$ were very low because this region is known to be affected by considerable phenotypic variability caused by the major component of milk (i.e., water). The third region, MWIR-1 (a central part of the mid-infrared region spanning wavenumber 3,048 to $1,701 \times \mathrm{cm}^{-1}$, corresponding to wavelengths from 3.281 to $5.878 \mu \mathrm{m}$ and frequencies from 91.4 to $51.0 \mathrm{THz}$ ), was characterized by variable correlations with RCT, mainly negative, exceeding in several cases the value of -0.50 . The fourth, MWIR-2 (wavenumber 1,698 to $1,586 \times \mathrm{cm}^{-1}$, corresponding to wavelengths 5.891 to $6.307 \mu \mathrm{m}$ and frequencies from 50.9 to $47.5 \mathrm{THz}$ ), was a very short region affected by water and it yielded almost null correlations. Lastly, the MWIR-LWIR region (spanning from wavenumber 1,582 to $930 \times \mathrm{cm}^{-1}$, corresponding to wavelengths 6.322 to $10.76 \mu \mathrm{m}$ and frequencies from 47.4 to $27.9 \mathrm{THz}$ ) was characterized by variable correlations with RCT, both positive and negative, always in the range -0.50 to +0.50 .

Use of the BayesB model allowed us to identify the combination of individual waves whose absorbance best predicts the studied trait. Figure 2 shows that

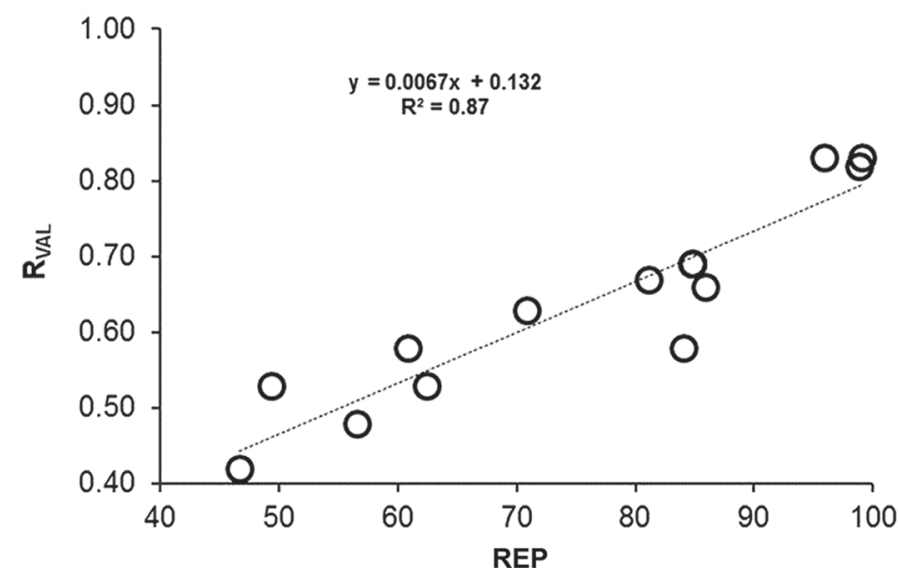

Figure 1. Correlations between coefficient of correlation of validation $\left(\mathrm{R}_{\mathrm{VAL}}\right)$ and repeatability of measured traits (REP). a few waves had calibration coefficients much higher than the others. Figure 2, which relates to the RCT of sheep milk, shows the Pearson correlations and BayesB coefficients to have many similarities with the figures reported by Ferragina et al. (2015) for the RCT of cow milk.

Comparing the graphs for the traditional single-point MCP (Figure 2: RCT, $\mathrm{k}_{20}$, and $\mathrm{a}_{30} ; \mathrm{a}_{45}$ and $\mathrm{a}_{60}$ are not shown because of their similarity with $\mathrm{a}_{30}$ ), the parameters of the $\mathrm{CF}_{\mathrm{t}}$ model equations (Figure $3: \mathrm{CF}_{\mathrm{P}}, \mathrm{k}_{\mathrm{CF}}$, and $\mathrm{k}_{\mathrm{SR}} ; \mathrm{RCT}_{\mathrm{eq}}$ is not shown because of its similarity with $\mathrm{RCT}$ ), and the derived traits (Figure 4: $\mathrm{CF}_{\max }$, and $t_{\max }$ ), it should be noted that the regions of the milk spectrum were characterized by different wave incidences with large coefficients, and that only some waves were selected for the prediction of different traits.

In particular, the waves of the SWIR region, despite frequent good Pearson correlations, were never selected because of high coefficients for any of the studied traits. The same occurred for the SWIR-MWIR region (first water region), which is often discarded before calibration (Karoui et al., 2010).

The MWIR-1 region was, on the contrary, very important for MCP calibration with the BayesB model, as it yielded several waves that are very important for various MCP traits. The most important is the wavenumber in the range of 2,963 to $2,951 \times \mathrm{cm}^{-1}$ (corresponding to wavelengths 3.37 to $3.39 \mu \mathrm{m}$ ). Among the 5 most important waves for calibrating each one of the various traits, this wave region was selected for 8 out of the 14 traits studied, and was the most important wave for 4 traits $\left(\mathrm{k}_{20}\right.$ and $\mathrm{RCT}_{\mathrm{eq}}-3 \mathrm{p}$, with positive coefficients, and $\mathrm{CF}_{\mathrm{P}}-3 \mathrm{p}$ and $\mathrm{CF}_{\mathrm{P}}-4 \mathrm{p}$, with negative coefficients). Moreover, 3 very close individual waves were selected in this interval for calibrating $\mathrm{CF}_{\max }$ derived traits $\left(2,963,2,955\right.$, and $\left.2,951 \times \mathrm{cm}^{-1}\right)$. These waves are in an area known for being affected by $\mathrm{C}-\mathrm{H}$ bonds (Bittante and Cecchinato, 2013) and close to the area known as "fat B" $\left(2,870-2,778 \times \mathrm{cm}^{-1}\right)$, which, through specific filters, is used to analyze the fat content in milk (Lynch et al., 2006; Kaylegian et al., 2009). Three areas in the wavenumber range 2,577 to $2,357 \times \mathrm{cm}^{-1}$ (corresponding to wavelengths 3.88 to $4.24 \mu \mathrm{m}$ ) were often selected: 2,577 to $2562,2,465$ to 2,422 , and 2,365 to $2,357 \times \mathrm{cm}^{-1}$. These were present in the first 5 calibration waves in 7 out of $14 \mathrm{MCP}$ traits (5 of which differ from those predicted on the basis of absorbance at $2,963-2,951 \times \mathrm{cm}^{-1}$ ). Three out of the 5 major calibration waves belong to this range for $\mathrm{a}_{45}, \mathrm{a}_{60}$, and $\mathrm{k}_{\mathrm{SR}}$, 2 of them for $\mathrm{k}_{\mathrm{CF}}-4 \mathrm{p}$ and $\mathrm{t}_{\max }$. This area of the milk spectrum, which is not known for specific relationships with milk chemical composition, is also found to be important for predicting the RCT of bovine milk, as well as cheese yield and the percentage recovery of milk fat 

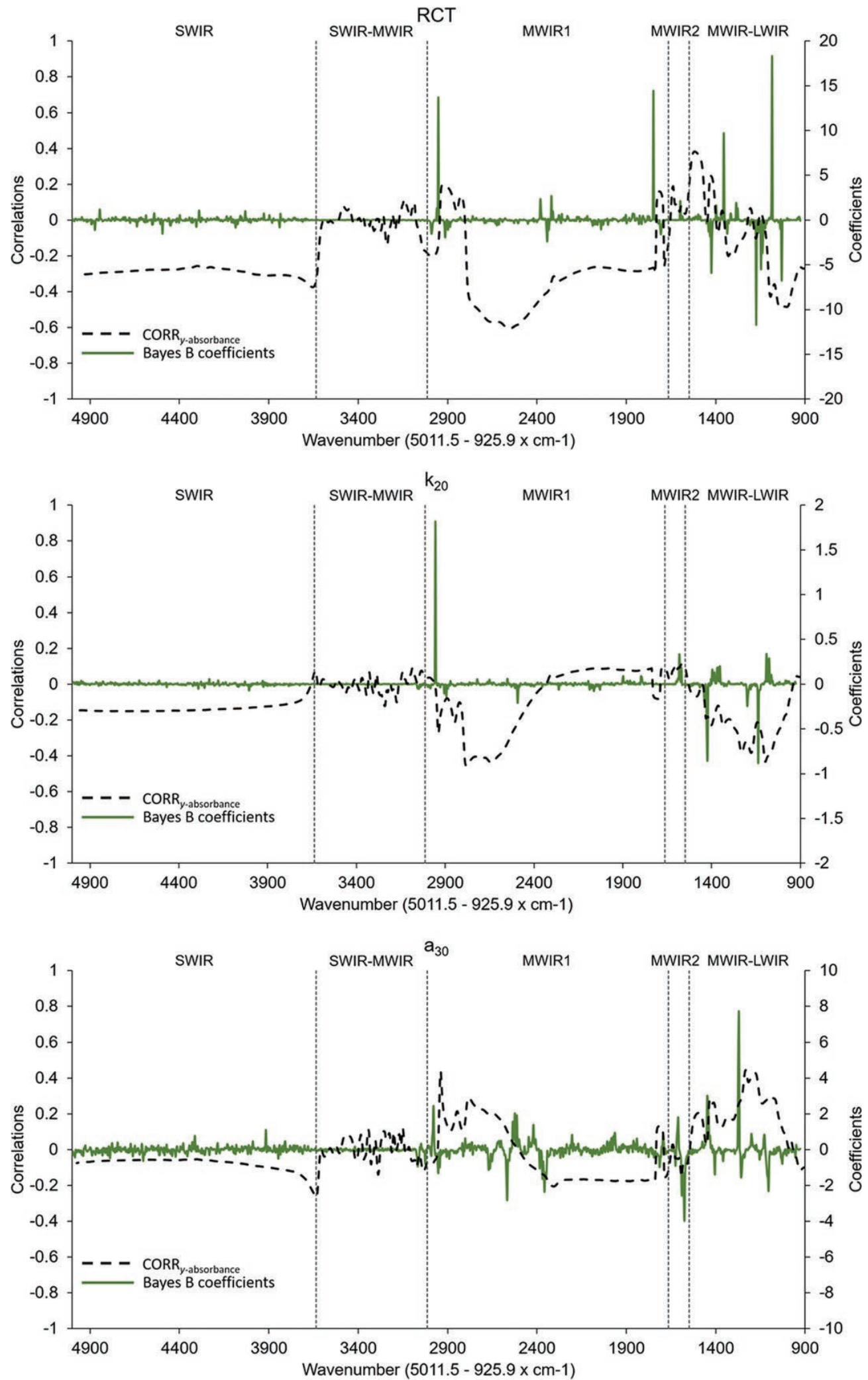

Figure 2. Graphical representation of 1,060 Pearson correlations (dashed/black line) between traditional milk coagulation properties $(\mathrm{RCT}=$ rennet coagulation time; $\mathrm{k}_{20}=$ curd firming time; $\mathrm{a}_{30}=$ curd firmness $30 \mathrm{~min}$ after rennet addition) and Fourier transform infrared absorbance of waves (5,000 to $930 \times \mathrm{cm}^{-1}$ ), and of calibration coefficients (solid/green curve) obtained according to BayesB model. SWIR, MWIR, and LWIR $=$ short-, mid-, and long-wave infrared regions, respectively. Color version available online. 

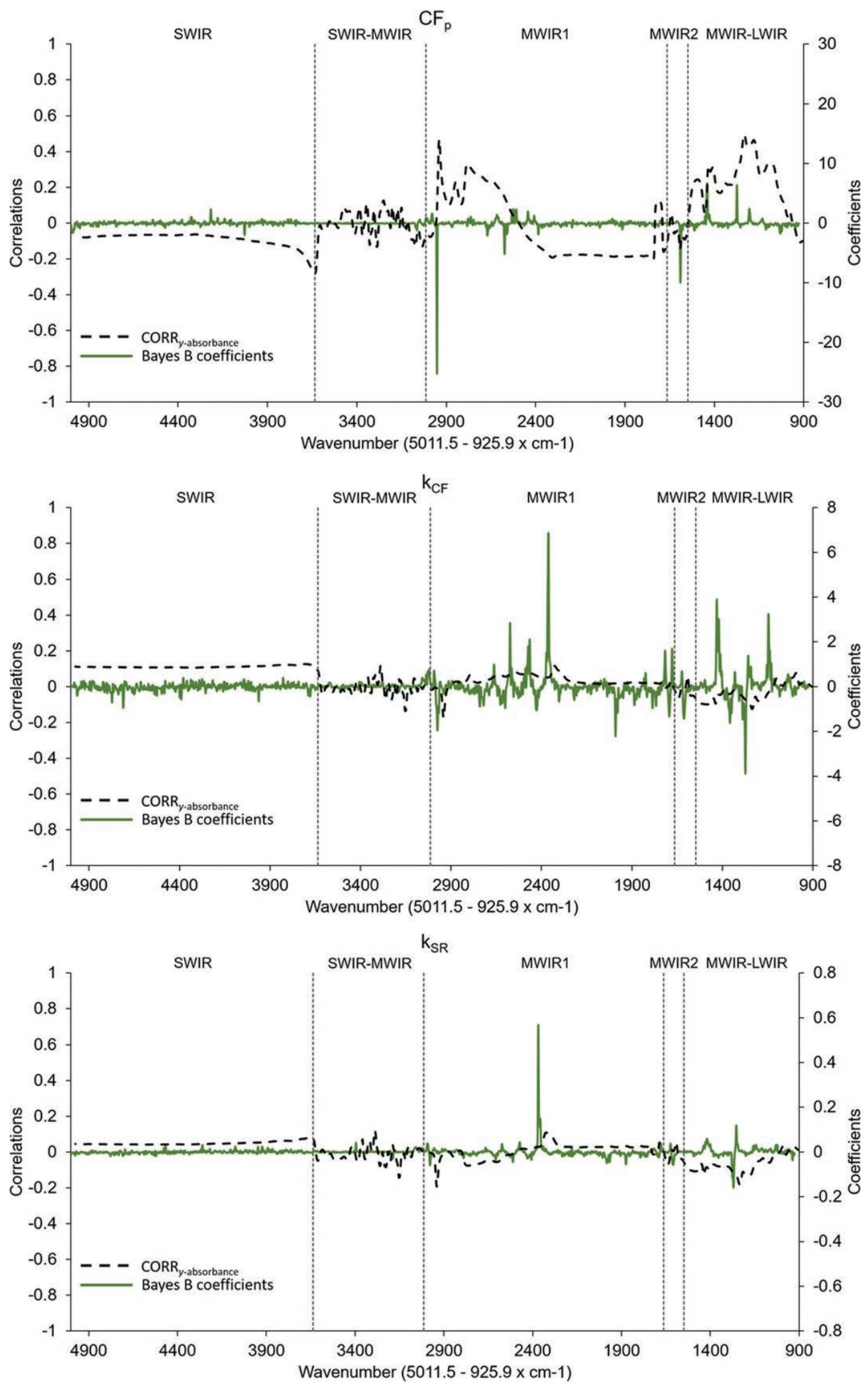

Figure 3. Graphical representation of 1,060 Pearson correlations (dashed/black line) between curd-firming parameters $\left(\mathrm{CF}_{\mathrm{p}}=\operatorname{asymptotical}\right.$ curd firmness; $\mathrm{k}_{\mathrm{CF}}=$ instant curd firming rate constant; $\mathrm{k}_{\mathrm{SR}}=$ instant syneresis rate constant) and Fourier transform infrared absorbance of waves $\left(5,000\right.$ to $\left.930 \times \mathrm{cm}^{-1}\right)$, and of calibration coefficients (solid/green curve) obtained according to BayesB model. SWIR, MWIR, and LWIR $=$ short-, mid-, and long-wave infrared regions, respectively. Color version available online. 
and protein in cheese (Ferragina et al., 2015). Finally, another individual wave in the MWIR-1 region of the milk spectrum (wavenumber $1,748 \times \mathrm{cm}^{-1}$, corresponding to wavelength $5.72 \mu \mathrm{m}$ ) was found to affect MCP calibration. In particular, this wave yielded the highest or second highest coefficient for predicting RCT and $\mathrm{RCT}_{\text {eq }}-4 \mathrm{p}$ (positive) and $\mathrm{k}_{\mathrm{CF}^{-}}-3 \mathrm{p}$ (negative). This wave is within the area known as "fat A" $\left(1,786-1,725 \times \mathrm{cm}^{-1}\right)$ in the prediction of milk composition using specific filtered waves from the MIR spectrum (Lynch et al., 2006; Kaylegian et al., 2009).

The FTIR spectrum region MWIR-2 is, such as the SWIR-MWIR region, characterized by water interfer- ence so that it is often excluded in the calibration (Karoui et al., 2010). Also, in the present study, this region was characterized by a very high absorbance variability, almost null correlations between individual wave absorbance and MCP traits, and the absence of important waves for the BayesB calibration method (Figure 2, 3 and 4). One exception was the interval from 1,593 to $1,574 \times \mathrm{cm}^{-1}$, which is on the border with the last region of the FTIR spectrum (mid- to long-infrared, MWIR-LWIR, from wavenumber 1,582 to $930 \times \mathrm{cm}^{-1}$, corresponding to wavelengths 6.322 to $10.76 \mu \mathrm{m}$ and frequency 47.4 to $27.9 \mathrm{THz}$ ). Discarding all the absorbances of the second water region,
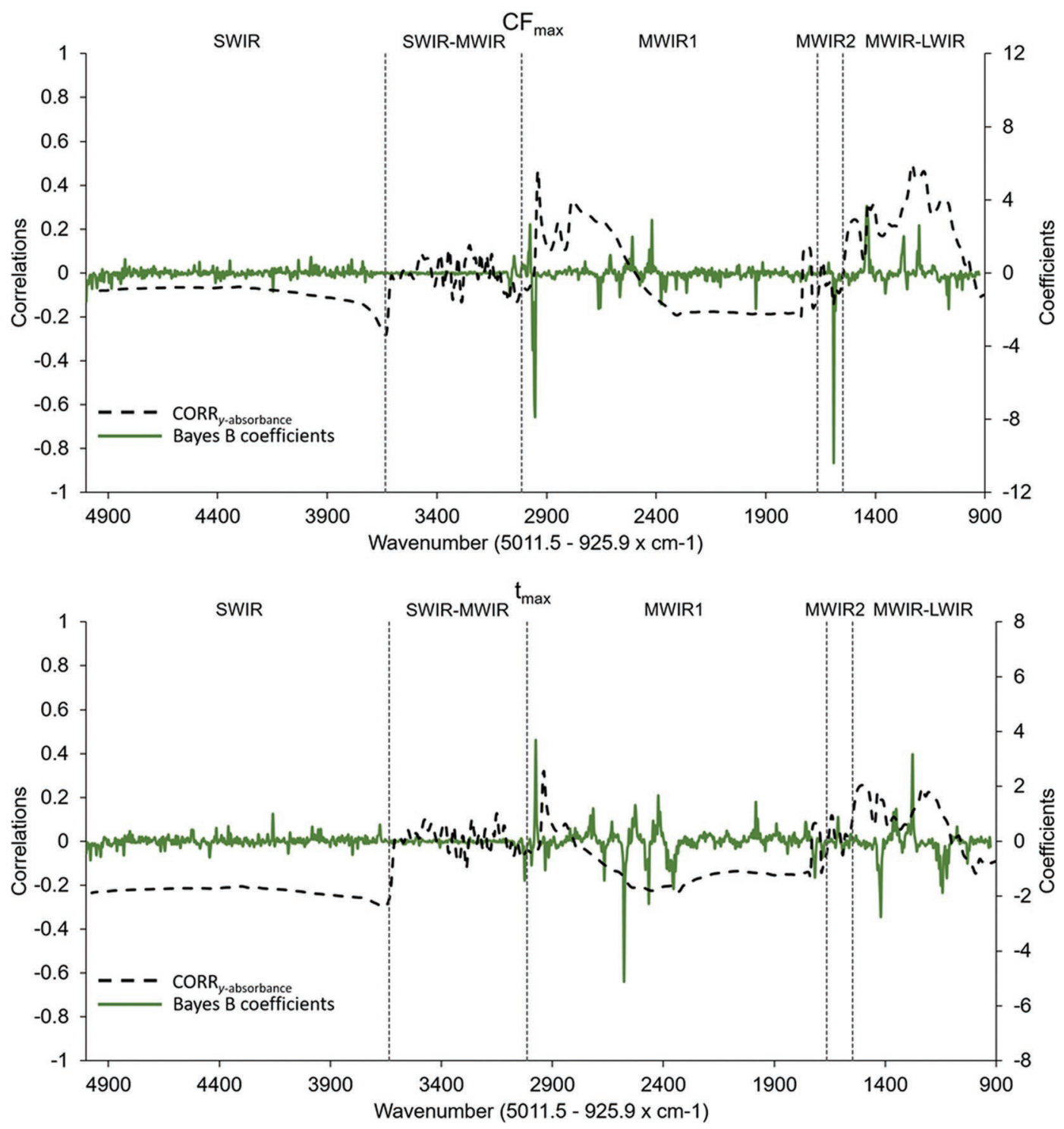

Figure 4. Graphical representation of 1,060 Pearson correlations (dashed/black line) between the curd-firming derived traits $\left(\mathrm{CF}_{\max }=\operatorname{maxi}\right.$ mum curd firmness; $\mathrm{t}_{\max }=$ time from rennet addition to the attainment of the $\left.\mathrm{CF}_{\max }\right)$ and Fourier transform infrared absorbance of waves $(5,000$ to $930 \times \mathrm{cm}^{-1}$ ), and of calibration coefficients (solid/green curve) obtained according to BayesB model. SWIR, MWIR, and LWIR $=$ short-, mid-, and long-wave infrared regions, respectively. Color version available online. 
often done before applying the partial least squares regression technique, would have entailed the loss of important information in predicting 3 out of the 4 MCP traits affected by these waves $\left(\mathrm{CF}_{\max }\right.$, the most important wave, $\mathrm{CF}_{\mathrm{P}}-4 \mathrm{p}$, the second most important, $\mathrm{CF}_{\mathrm{P}}-3 \mathrm{p}, 2$ waves, and $\mathrm{a}_{30}$, the third wave). Bittante and Cecchinato (2013) and, more recently, Wang et al. (2016) found that the spectral areas typical of the water absorption bands contain important information; thus, although in some cases better prediction can be obtained by deleting these areas, important information, mainly genetic, is lost. Using the BayesB model allowed the entire FTIR spectrum to be used without any deletion or data pretreatment.

In the MWIR-LWIR region, the correlations between all wave absorbances and MCP traits were extremely variable, with several individual waves selected by the BayesB model in the area from wavenumber 1,447 to $1,080 \times \mathrm{cm}^{-1}$ (corresponding to wavelengths 6.91 to $9.25 \mu \mathrm{m})$. In particular, the waves 1,447 to $1,420 \times$ $\mathrm{cm}^{-1}$ affected the majority of the MCP studied (9 out of 14) and are close to the interval $(1,547-1,478 \times$ $\mathrm{cm}^{-1}$ ) used for predicting milk protein using filters to limit the MIR spectra (Lynch et al., 2006; Kaylegian et al., 2009). In addition, the waves 1,277 to $1,256,1,173$ to 1,122 , and 1,091 to $1,080 \times \mathrm{cm}^{-1}$ affected prediction of all MCP traits with the exception of $\mathrm{CF}_{\mathrm{P}}-3 \mathrm{p}$ and $\mathrm{CF}_{\max }$. This spectral area has also been found to be important for predicting cheese yield traits and the content of some fatty acids in bovine milk (Ferragina et al., 2015).

\section{Use of FTIR-Predicted Traits for the Dairy Sector}

Although the repeatability of FTIR-predicted MCP traits was high, the variable correlations between the predicted and measured traits in the external data set, those not used for calibration, highlighted a few issues regarding effective utilization of these data. The parameters often used for evaluating the feasibility of infrared predictions (Williams and Norris, 2001; Karoui et al., 2006) are the ratio of performance deviation, the range error ratio, the relative prediction error, and the concordance correlation coefficient. The principle of each parameter is to quantify the prediction error without taking into account the analytical error of the golden standard method (assumed to be the real value of the sample). According to this principle, only RCT, especially if estimated from the model, could be considered useful in practice (e.g., for genetic selection and the milk payment scheme). In the case of MCP traits, we showed that instrumental repeatability was very high only for RCT, especially if obtained through $\mathrm{CF}_{\mathrm{t}}$ modeling, whereas it was far from $100 \%$ for all the other traits, and less than $50 \%$ in the case of $\mathrm{a}_{60}$ and $\mathrm{k}_{\mathrm{SR}}$ (Table 2). It was clear that the repeatability of the golden standard measures should be taken into account when evaluating the usefulness of the predicted traits. The $R_{\mathrm{VAL}}$ coefficient (Table 1 ) was not much lower than instrumental repeatability (Table 2), especially for low repeatability traits. In these conditions, the FTIR predictions could be a useful alternative to instrumental testing, but further research is needed in the future.

In the case of genetic selection, the heritability of predicted traits was shown to be similar to or better than that of measured traits in dairy cattle. The most important finding is that the genetic correlations between measured and predicted traits are usually higher than the phenotypic correlations for MCP (Cecchinato et al., 2009). In the case of ovine milk, it has not yet been directly shown that FTIR-predicted traits can yield genetic information close to that obtained from measured traits. Given the finding that the heritability of ovine MCP is similar to that obtained in bovine species (Bittante et al., 2016) and the similarity of prediction accuracies obtained in the present study, it could be very interesting address future research in testing FTIR predictions for genetic selection in the ovine species. This is potentially important for the dairy industry because direct selection based on measured traits is not feasible due to the high cost and sampling problems.

\section{CONCLUSIONS}

The present study has shown in ovine milk, for the first time, that FTIR spectroscopy, coupled with advanced Bayesian chemometric models, offers the possibility to predict all traditional and new lactodynamographic traits. Prediction accuracy is variable, high for milk rennet coagulation time, but lower for the other measured traits. Nevertheless, accuracy of calibration and cross-validation, and external validation of the various traits tested in ovine milk were similar to or greater than those obtained in bovine milk. We also confirmed that the first determinant of prediction accuracy is repeatability of the gold standard analyses used for calibration. In any case, the repeatability of predicted traits is generally high for all traits, including those characterized by low analytical repeatability. In conclusion, FTIR spectroscopy allows us to analyze ovine milk rapidly and cheaply, and, furthermore, it is possible to apply it directly to samples collected for milk recording. It allows us to obtain large individual data sets that could be used for genetic selection of traits that are important for the ovine dairy industry, such as milk coagulation, curd firming, and syneresis. The more accurate predictions could also be incorporated into the milk payment scheme. 


\section{ACKNOWLEDGMENTS}

This research was supported by a grant from the Fondazione di Sardegna (Sardinia Foundation, Sassari, Italy). The authors thank the farmers for giving access to their flocks, the A.I.P.A./A.P.A.s (Provincial Livestock Farmers' Associations) of Cagliari, Nuoro, Sassari, and Oristano (Italy) for their support in sample collection, A.R.A. Sardegna, Cagliari, Italy (Regional Livestock Farmer' Association of Sardinia) for support in milk analysis, Gustavo de los Campos and Ana I. Vazquez (Epidemiology and Biostatistics Department, and Department of Statistics and Probability, Michigan State University, respectively) for their assistance regarding Bayesian analysis.

\section{REFERENCES}

Abilleira, E., M. Virto, A. I. Nájera, J. Salmerón, M. Albisu, F. J. Pérez-Elortondo, J. C. Ruiz de Gordoa, M. de Renobales, and L. J. R. Barron. 2010. Effects of seasonal changes in feeding management under part-time grazing on the evolution of the composition and coagulation properties of raw milk from ewes. J. Dairy Sci. 93:3902-3909.

Battacone, G., E. A. Cannas, A. Mazzette, C. Dimauro, and G. Enne. 2005. Why does the increase of plasmin worsen the coagulation properties of milk in dairy sheep? Ital. J. Anim. Sci. 4:342-344.

Bencini, R. 2002. Factors affecting the clotting properties of sheep milk. J. Sci. Food Agric. 82:705-712.

Bittante, G. 2011. Modeling rennet coagulation time and curd firmness of milk. J. Dairy Sci. 94:5821-5832.

Bittante, G., and A. Cecchinato. 2013. Genetic analysis of the Fouriertransform infrared spectra of bovine milk with emphasis on individual wavelengths related to specific chemical bonds. J. Dairy Sci. 96:5991-6006.

Bittante, G., C. Cipolat-Gotet, M. Pazzola, M. L. Dettori, G. M. Vacca, and A. Cecchinato. 2016. Genetic analysis of coagulation properties, curd firming modeling, milk yield, composition and acidity in Sarda dairy sheep. J. Dairy Sci. 100:385-394.

Bittante, G., B. Contiero, and A. Cecchinato. 2013. Prolonged observation and modelling of milk coagulation, curd firming, and syneresis. Int. Dairy J. 29:115-123.

Bittante, G., E. Pellattiero, F. Malchiodi, C. Cipolat-Gotet, M. Pazzola, G. M. Vacca, S. Schiavon, and A. Cecchinato. 2014. Quality traits and modeling of coagulation, curd firming, and syneresis of sheep milk of Alpine breeds fed diets supplemented with rumenprotected conjugated fatty acid. J. Dairy Sci. 97:4018-4028.

Bittante, G., M. Penasa, and A. Cecchinato. 2012. Invited review: Genetics and modeling of milk coagulation properties. J. Dairy Sci. 95:6843-6870.

Caredda, M., M. Addis, I. Ibba, R. Leardi, M. F. Scintu, G. Piredda, and G. Sanna. 2016. Prediction of fatty acid in sheep milk by midinfrared spectrometry with a selection of wavelengths by genetic algorithms. LWT Food Sci. Technol. (Campinas) 65:503-510.

Carta, A., S. Casu, M. G. Usai, M. Addis, M. Fiori, A. Fraghì, S. Miari, L. Mura, G. Piredda, L. Schibler, T. Sechi, J. M. Elsen, and F. Barillet. 2008. Investigating the genetic component of fatty acid content in sheep milk. Small Rumin. Res. 79:22-28.

Cecchinato, A., M. De Marchi, L. Gallo, G. Bittante, and P. Carnier. 2009. Mid-infrared spectroscopy predictions as indicator traits in breeding programs for enhanced coagulation properties of milk. J. Dairy Sci. 92:5304-5313.

Dal Zotto, R., M. De Marchi, A. Cecchinato, M. Penasa, M. Cassandro, P. Carnier, L. Gallo, and G. Bittante. 2008. Reproducibility and repeatability of measures of milk coagulation properties and predictive ability of mid-infrared reflectance spectroscopy. J. Dairy Sci. 91:4103-4112.

de los Campos, G., and P. Perez Rodriguez. 2015. BGLR: Bayesian Generalized Linear Regression. R package version 1.0.4. Accessed Sep. 20, 2015. http://CRAN.R-project.org/package=BGLR

De Marchi, M., V. Toffanin, M. Cassandro, and M. Penasa. 2014 Invited review: Mid-infrared spectroscopy as phenotyping tool for milk traits. J. Dairy Sci. 97:1171-1186.

FAOSTAT. 2015. Statistical database of the Food and Agriculture Organization of the United Nations. Accessed Sep. 20, 2015. http:// faostat.fao.org/.

Ferragina, A., G. de los Campos, A. I. Vazquez, A. Cecchinato, and G. Bittante. 2015. Bayesian regression models outperform partial least squares methods for predicting milk components and technological properties using infrared spectral data. J. Dairy Sci. 98:8133-8151.

Ferrand-Calmels, M., I. Palhière, M. Brochard, O. Leray, J. M. Astruc, M. R. Aurel, S. Barbey, F. Bouvier, P. Brunsching, H. Caillat, M. Douguet, G. Faucon-Lahalle, M. Gelé, G. Thomas, J. M. Trommenschlager, and H. Larroque. 2014. Prediction of fatty acid profiles in cow, ewe, and goat milk by mid-infrared spectrometry. J. Dairy Sci. 97:17-35.

ICAR. 2012. International Committee for Animal Recording. International agreement of recording practices - Guideline approved by the general assembly held in Cork, Ireland on June 2012. ICAR, Rome, Italy.

ISO. 2002. ISO 5765-2:2002 (IDF 79-2:2002). Dried milk, dried icemixes and processed cheese. Determination of lactose content. Part 2: Enzymatic method utilizing the galactose moiety of the lactose. International Organisation for Standardisation, Geneva, Switzerland.

ISO. 2004. ISO 17997-1:2004 (IDF 29-1:2004). Milk. Determination of caseinnitrogen content. Part 1: Indirect method (Reference method). International Organisation for Standardisation, Geneva, Switzerland.

ISO. 2010. ISO 1211:2010 (IDF 1:2010). Milk. Determination of fat content. Gravimetric method (Reference method). International Organisation for Standardisation, Geneva, Switzerland.

ISO. 2014. ISO 8968-1:2014 (IDF 20-1:2014). Milk and milk products. Determination of nitrogen content. Part 1: Kjeldahl principle and crude protein calculation. International Organisation for Standardisation, Geneva, Switzerland.

Jaramillo, D. P., A. Zamora, B. Guamis, M. Rodríguez, and A. J. Trujillo. 2008. Cheesemaking aptitude of two Spanish dairy ewe breeds: Changes during lactation and relationship between physico-chemical and technological properties. Small Rumin. Res. 78:48-55.

Karoui, R., G. Downey, and C. Blecker. 2010. Mid-infrared spectroscopy coupled with chemometrics: A tool for the analysis of intact food systems and the exploration of their molecular structure-quality relationships-A review. Chem. Rev. 110:6144-6168.

Karoui, R., A. M. Mouazen, E. Dufour, L. Pillonel, D. Picque, J. De Baerdemaeker, and J.-O. Bosset. 2006. Application of the MIR for the determination of some chemical parameters in European Emmental cheeses produced during summer. Eur. Food Res. Technol. 222:165-170.

Kaylegian, K. E., J. M. Lynch, J. R. Fleming, and D. M. Barbano. 2009. Influence of fatty acid chain length and unsaturation on midinfrared milk analysis. J. Dairy Sci. 92:2485-2501.

Lerma-García, M. J., A. Gori, L. Cerretani, E. F. Simç-Alfonso, and M. F. Carboni. 2010. Classification of Pecorino cheeses produced in Italy according to their ripening time and manufacturing technique using Fourier transform infrared spectroscopy. J. Dairy Sci. 93:4490-4496.

Lynch, J. M., D. M. Barbano, M. Schweisthal, and J. R. Fleming. 2006. Precalibration evaluation procedures for mid-infrared milk analyzers. J. Dairy Sci. 89:2761-2774.

Manca, M. G., J. Serdino, G. Gaspa, P. Urgeghe, I. Ibba, M. Contu, P. Fresi, and N. P. P. Macciotta. 2016. Derivation of multivariate indices of milk composition, coagulation properties, and individual cheese yield in dairy sheep. J. Dairy Sci. 99:4547-4557. 
Nicolaou, N., Y. Xu, and R. Goodacre. 2010. Fourier transform infrared spectroscopy and multivariate analysis for the detection and quantification of different milk species. J. Dairy Sci. 93:5651-5660.

Pazzola, M., M. L. Dettori, C. Cipolat-Gotet, A. Cecchinato, G. Bittante, and G. M. Vacca. 2014. Phenotypic factors affecting coagulation properties of milk from Sarda ewes. J. Dairy Sci. 97:72477257.

Pellegrini, O., O. Remeuf, M. Rivemale, and F. Barillet. 1997. Renneting properties of milk from individual ewes: Influence of genetic and non-genetic variables, and relationship with physicochemical characteristics. J. Dairy Res. 64:355-366.

R Core Team. 2015. R: A language and environment for statistical computing. R Foundation for Statistical Computing, Vienna, Austria. Accessed Sep. 20, 2015. http://www.R-project.org/.

Sevi, A., L. Taibi, M. Albenzio, A. Muscio, and G. Annicchiarico. 2000 Effect of parity on milk yield, composition, somatic cell count, renneting parameters and bacteria counts of Comisana ewes. Small Rumin. Res. 37:99-107.

Stocco, G., C. Cipolat-Gotet, T. Bobbo, A. Cecchinato, and G. Bittante. 2017. Herd productivity and breed of cows affect milk composition, coagulation properties and curd firming and syneresis modeling. J. Dairy Sci. 100:129-145. https://doi.org/10.3168/ jds.2016-11662.

Stocco, G., C. Cipolat-Gotet, A. Cecchinato, L. Calamari, and G. Bittante. 2015. Milk skimming, heating, acidification, lysozyme, and rennet affect the pattern, repeatability, and predictability of milk coagulation properties and of curd-firming model parameters: A case study of Grana Padano. J. Dairy Sci. 98:5052-5067.

Vacca, G. M., M. Pazzola, M. L. Dettori, E. Pira, F. Malchiodi, C. Cipolat-Gotet, A. Cecchinato, and G. Bittante. 2015. Modeling of coagulation, curd firming, and syneresis of milk from Sarda ewes. J. Dairy Sci. 98:2245-2259

Wang, Q., A. Hulzebosh, and H. Bovenhuis. 2016. Genetic and environmental variation in bovine milk infrared spectra. J. Dairy Sci. 99:6793-6803.

Williams, P. C., and K. Norris. 2001. Near-Infrared Technology in the Agricultural and Food Industries. 2nd ed. American Association of Cereal Chemists, St. Paul, MN.

Zhang, R. H., A. F. Mustafa, K. F. Ng-Kwai-Hang, and X. Zhao. 2006. Effects of freezing on composition and fatty acid profile of sheep milk and cheese. Small Rumin. Res. 64:203-210. 